\title{
Spectral characteristics of spring arctic mesosphere dynamics
}

\author{
C. M. Hall ${ }^{1}$, A. H. Manson ${ }^{2}$ and C. E. Meek ${ }^{2}$ \\ ${ }^{1}$ The Auroral Observatory, Department of Physics, University of Tromsø, 9037 Tromsø, Norway \\ e-mail chris.hall@phys.uit.no \\ ${ }^{2}$ Institute of Space and Atmospheric Studies, University of Saskatchewan, Saskatoon, Saskatchewan, Canada
}

Received: 6 January 1998 / Revised: 10 April 1998 / Accepted: 27 April 1998

\begin{abstract}
The spring of 1997 has represented a stable period of operation for the joint University of Tromsø / University of Saskatchewan MF radar, being between refurbishment and upgrades. We examine the horizontal winds from the February to June inclusive and also include estimates of energy dissipation rates derived from signal fading times and presented as upper limits on the turbulent energy dissipation rate, $\varepsilon$. Here we address the periodicity in the dynamics of the upper mesosphere for time scales from hours to one month. Thus, we are able to examine the changes in the spectral signature of the mesospheric dynamics during the transition from winter to summer states.
\end{abstract}

Key words. Meteorology and atmospheric dynamics (middle atmosphere dynamics; turbulence; waves and tides).

\section{Introduction}

The joint University of Tromsø/University of Saskatchewan MF radar, located in northern Norway at $69^{\circ} \mathrm{N}$ $19^{\circ} \mathrm{E}$, has, during the winter of $1996 / 7$, been refurbished to some degree. This has meant that the data quality, particularly its reliability, and accessibility for ease of analysis has been greatly improved. During the autumn of 1997 the transmitter antenna array has been refurbished resulting in a slightly altered beam shape. Subsequently changes have been made to the receiver software and firmware. Due to these various changes, it is timely to examine the data from the spring of 1997 , this being a time of high data reliability combined with a

Correspondence to: $\mathrm{C}$. M. Hall well-tested system of fixed specification. Table 1 gives the specification of the radar for this period. The salient points of Table 1, for the purposes of this study, are the final height and time resolutions of $3 \mathrm{~km}$ and $5 \mathrm{~min}$ respectively. Winds are determined by the spaced antenna method elegantly described by Hocking (1997) using the full correlation analysis (FCA) described by Briggs (1984). The radar operates unattended round the clock so that 288 wind profiles are available each day. Not each profile is complete, however, because of either poor signal-to-noise ratios (typical at night in winter) or due to total reflection of the signal (during periods of high auroral activity). In order to look for any changes in dynamics during the spring, we have chosen to make monthly averages. We form spectra for the months of February to June inclusive and at selected heights. Above $95 \mathrm{~km}$ there is a danger that total reflection of the signal has occurred, or at least, the virtual height of the measurement is no longer representative of the true height. Below $75 \mathrm{~km}$, the data tends to be sparse due to lack of ionisation. We will only present data from the gates between $76 \mathrm{~km}$ and $91 \mathrm{~km}$ inclusive. It should be stressed that this data selection was made in order to address dynamics with time scales from the order of hours (e.g. the terdiurnal tidal mode) up to 2 to 3 weeks; it is obviously of interest to examine the way the gravity wave field changes during the equinox, but this will be left to a future study. Similarly, longer periodicity is evident in our data, but we wish to establish the success of our system modifications before extending the dataset. Seasonal and inter-annual variation studies will also be deferred, therefore.

The published data for the latitudes near $70^{\circ} \mathrm{N}$, on locally observed oscillations at tidal and planetary wave (PW) periods, are still rather limited. Some climatologies were prepared for the MAP programme (1982-85), and were summarized by Avery et al. (1989): the stations included mainly Mawson $\left(67^{\circ} \mathrm{S}\right)$, Poker Flat $\left(65^{\circ} \mathrm{N}\right)$ and Troms $\varnothing\left(69^{\circ} \mathrm{N}\right)$. Briefly, these involved contour plots (with 10-30-day resolution) of 12-, 24-h tidal oscillations (amplitudes and phases). Features for the Northern 
Table 1. Specification of radar spring 1997

\begin{tabular}{ll}
\hline Geographic co-ordinates & $69.58^{\circ} \mathrm{N}, 19.22^{\circ} \mathrm{E}$ \\
Operating frequency & $2.8 \mathrm{MHz}$ \\
Pulse repetition frequency & $100 \mathrm{~Hz}$ \\
Peak transmitter power & $\sim 60 \mathrm{~kW}$ \\
Transmitter antenna beamwidth & $17^{\circ}$ \\
Receiver antenna & $3 \mathrm{spaced}$ inverted-V dipoles \\
Height resolution & $3 \mathrm{~km}$ \\
Post-integration time & $5 \mathrm{~min}$ \\
\hline
\end{tabular}

Hemisphere included rather smaller amplitudes compared to mid-latitudes and a tendency toward longer wavelengths or even evanescence during the summer months. Otherwise the seasonal variations were reported to be rather similar to those well-demonstrated for the mid-latitudes $\left(40^{\circ}-55^{\circ} \mathrm{N}\right)$, and included strong transitions during the equinoxes to well distinguished solstitial states (Manson et al., 1989). Some of these results, and the more recent ones from the improved Tromsø climatologies (Manson and Meek, 1991), will be compared to the new observations in later sections of this study. Planetary waves have been studied to only a limited extent near $70^{\circ} \mathrm{N}$. Significant papers include Williams and Avery (1992), and Espy et al. (1997). In the first paper (Poker Flat) Rossby normal-modes of 5and 16-day waves were observed (significantly) throughout the year, but with maxima in summer months; while the 1.8-2-day modes were prominent only in the summer months. Also Espy et al. (1997), observing in Northern Sweden, located the 16-day oscillation in summer polar mesospheric temperatures, and proposed (as did Williams and Avery 1992) propagation from the winter to summer hemispheres. Our results will be related to these previously published tidal and PW observations.

\section{Data processing}

As described already, we have selected data from a limited height regime, 76 to $91 \mathrm{~km}$, initially, and with the $3-\mathrm{km}$ height resolution of the instrument, this means 6 heights for each time step. The time series are divided into months, five in all. Again, as mentioned, data are not always available for each height and time, and therefore we have chosen to employ the periodogram analysis of Lomb and Scargle (Lomb, 1976), which is able to handle irregularly spaced data. This means, however, that the frequencies at which power spectral density is estimated are not always the same from month to month and from height to height. Furthermore, the algorithm yields power normalised to the total power. To make the derived spectra comparable with one another, therefore, we remove the normalisation by multiplying the amplitudes by the standard deviation of the original time series. In order to facilitate construction of contour plots of amplitude versus combinations of period, month and height, we then interpolate to a regular frequency grid. Since this interpolation has a tendency to introduce an undesirable degree of granularity at long periods (viz. over 1 week), we have also interpolated the amplitudes at specific frequencies, these being specified in Table 2, and chosen because they are identified as known modes of oscillation in the atmosphere (e.g. Forbes, 1995).

As an example of the original wind data, we show the zonal component of the wind at $90 \mathrm{~km}$ in Fig. 1. The annotation on the time axis indicates the end of the month (i.e. "1" indicates "end of January" and so on). Further to our earlier explanation of why only the data from February to June are selected: (a) prior to $1^{\text {st }}$ February, winter storms had damaged receiver antennae and the transmitter power was in question; (b) in late summer and early autumn, changes were made to the transmitter antenna; (c) in mid-summer PMSE are present which while really a characteristic of VHF backscatter, is an unknown element at MF (Bremer et al., 1997). Figure 1 is unlikely to be influenced by any PMSE effects (if there are such things) since $90 \mathrm{~km}$ is generally above the average PMSE height. In order to give adequate coverage of the whole spring period, we have included data from June despite it being a "PMSE month". In Fig. 2 to 6 we present the simplest representations of the data, with one figure for each month. Initially, we shall just look at the zonal wind component, this having the largest variance and most obvious periodicity. Each figure consists of two representations: spectra at each height followed by the combination of these into a single contour plot. Note that the scales are logarithmic. The reader is asked not to pay any attention to the amplitudes, but rather consider the emerging important frequencies. The simple line plots are included to indicate the noise level and therefore the confidence in the frequencies that we subsequently try to highlight in the plots that follow. The frequencies listed in Table 2 have been identified on the horizontal axes. Although the region of short periods (typically below 2 or $3 \mathrm{~h}$ ) appears to be the noise plateau, we have chosen to include it in all the

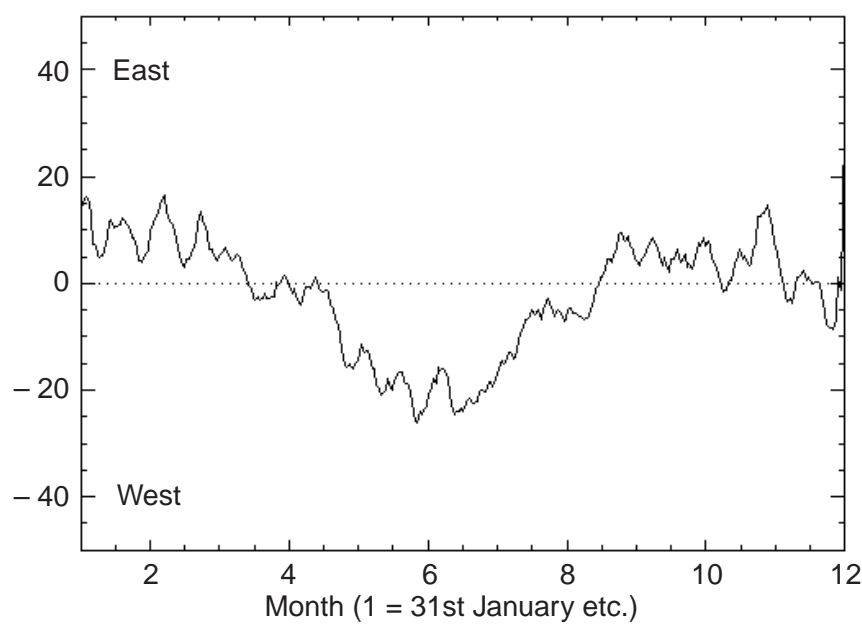

Fig. 1. Zonal wind at $90 \mathrm{~km}$ as a function of time. The data have been smoothed using a week wide window. The purpose of this figure is to indicate the general nature of the wind for each month. The annotation on the horizontal axis indicates the month endings, i.e. "l" "end-of-January" etc 

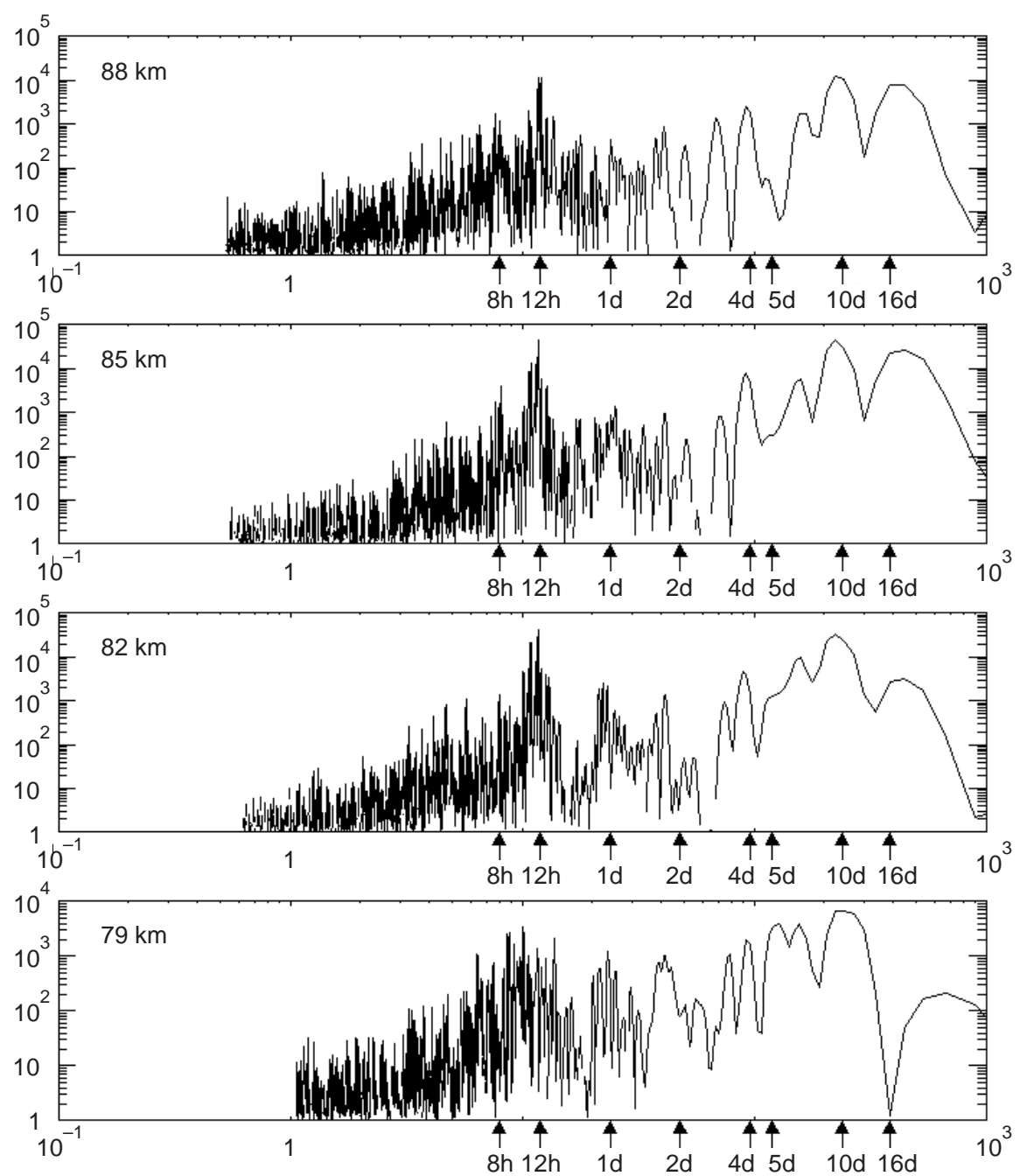

Fig. 2. Spectra of the (unsmoothed) zonal wind at a variety of heights for February 1997 plots. Any monochromatic features in this region would be expected to be short-lived and the averaging used here will produce a continuum. We shall not address such time scales here, but Manson and Meek (1997) have reported evidence of $-5 / 3$ spectral slopes in this regime. Looking at the data as a whole, we can see a hint of power law spectra at periods shorter than the shortest tidal mode. We see that there is considerable noise in the $76 \mathrm{~km}$ gate, that the frequencies evident in the higher gates are less clear here, and in the cases where obvious frequencies do indeed emerge, they are the same as in the $79 \mathrm{~km}$ spectra. Similarly, the emergent frequencies at $91 \mathrm{~km}$ are the same as those at $88 \mathrm{~km}$. Due to these observations from the inspection of the individual spectra, we shall restrict our discussion to the heights 79,8285 and $88 \mathrm{~km}$ from now on. This height regime should just span the summer mesopause at this latitude (Lübken and von Zahn, 1991).

\section{Interpretation}

As perhaps anticipated, the spectra in Figs. 2 to 6 show distinct signatures: a. In February, deemed to be representative of the winter state (recall that the radar was not operating optimally in January), we see a dominance of the semidiurnal tide at heights above $80 \mathrm{~km}$. Below $85 \mathrm{~km}$ the diurnal mode begins to emerge, and the $8 \mathrm{~h}$ tidal mode is evident above. There is a clear indication of a 10-day period below $90 \mathrm{~km}$, whereas a 16-day period seems to be present above $80 \mathrm{~km}$. The 4-day mode is visible at all heights.

b. In March, the situation begins to change noticeably at $85 \mathrm{~km}$ and above. Any indication of a terdiurnal mode has disappeared and the diurnal tide now competes with the semidiurnal tide for dominance. At longer time scales, a 5-day periodicity emerges lower down, the 4-day mode seen in February having disappeared. The roles of the 10 and 16-day oscillations reverse, the latter becoming especially clear around $85 \mathrm{~km}$.

c. In April, the semidiurnal and diurnal modes appear similarly to those in March at $85 \mathrm{~km}$ and above. Below $85 \mathrm{~km}$, these modes now dominate the whole spectrum. The 4, 5 and 16-day modes become less distinct, but the 10-day mode re-emerges above $80 \mathrm{~km}$. 

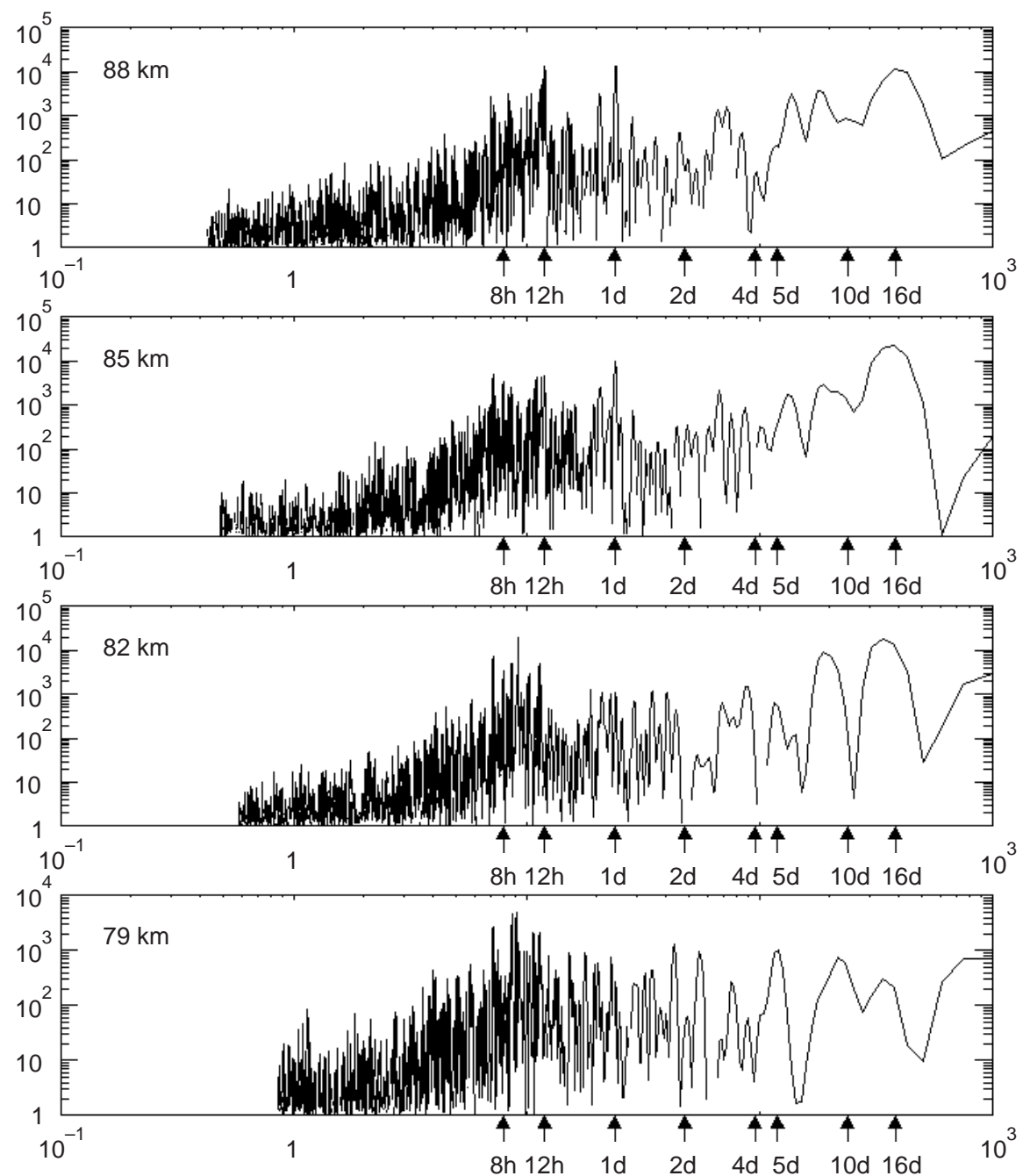

Fig. 3. As for Fig. 2 but for March 1997

d. In May, the tendency of April is reinforced at the tidal time scales, the diurnal mode now dominating the sub-summer mesopause heights. At longer time scales, the 5-day mode reasserts itself and 10 and 16 day modes are also evident.

e. In June, the summer dynamics are fully developed and the diurnal tide dominates throughout the upper mesosphere and lower thermosphere. The 16-day mode is evident at most heights. In addition a quasi 2-day oscillation appears.

These salient features may be compared with the overall picture of the zonal wind as seen in Fig. 1. During February and March the winds were exclusively eastwards; in June, the strong westward mesospheric jet was fully established. In between, in May, the westward nature became established and increased. In April, the wind oscillated between eastward and westward, the 10day variation evident from Fig. 4 rendering the reversal indistinct.

In order to examine this further, we therefore assemble, in Fig. 7, the spectra from a selection of heights and construct contour plots of spectral amplitude versus period and month. Since we have reduced the quantity of data the reader has to assimilate, we have introduced the meridional wind and kinetic energy dissipation rate as additional parameters. The latter is derived from the signal fading time, eddy diffusion being assumed to be responsible for dissipation of the scattering structures whose movement is otherwise traced in order to determine the horizontal wind. More details of the derivation of this parameter, which is intended as an upper limit to $\varepsilon$, the turbulent energy dissipation rate, is described by Hall et al. (1998). The energy dissipation rate used here may include gravity wave contributions and in the buoyancy sub-range not all energy is necessarily passed from larger to smaller scales as is the case for the inertial sub-range. Nevertheless, if we are to ignore the absolute magnitudes of the energy dissipation rate (to avoid the temptation of comparing it with other estimates of $\varepsilon$ ) and rather concentrate on spectral characteristics, we feel it worth including in our discussion. In Fig. 7, the colour scale is the same for all panels such that the relative amplitudes for different heights may also be compared. Perhaps the most obvious feature of this figure is the April "valley": much periodicity fades from March to April and reemerges in May. An exception to this is perhaps the diurnal mode that largely survives the transition period 

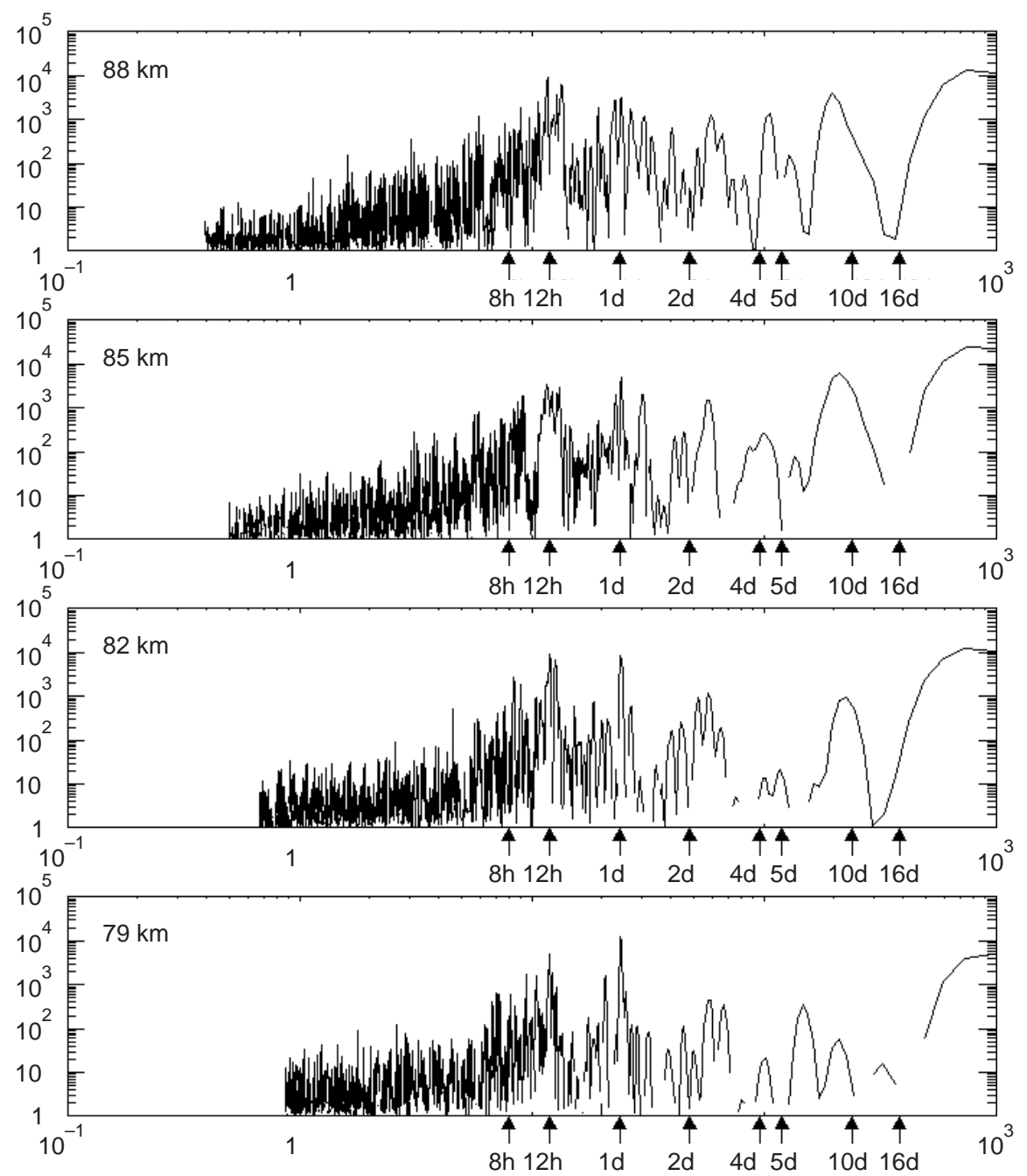

Fig. 4. As for Fig. 2 but for April 1997

throughout the upper mesosphere and for both wind components. Indeed, the diurnal tide is particularly obvious in the energy dissipation rate for all dates and heights. There is a tendency for the 10 and 16-day waves to be somewhat weaker in the summer state than the winter one. A less obvious feature is that the 4-day mode is quite persistent in the meridional wind as opposed to the zonal component. We should reiterate at this point that in order to construct these figures, we have interpolated to a regular grid thus imposing a granularity that may be slightly misleading at the longest time scales. In order to address this problem we have extracted the spectral amplitudes for the particular modes identified by Forbes (1995) and specified in our Table 2. Figure 8 shows these amplitudes as functions of month and height, with a set of three panels (the two wind components and the energy dissipation rate) for each of the four tidal periods (the 2-day mode being included here because it is a gravityRossby mode). Addressing each of these modes in turn, then:

1. The terdiurnal mode is most evident in the zonal wind and at any rate almost exclusively below $85 \mathrm{~km}$. It is suppressed in April, but in the summer state it appears in both the zonal wind and the energy dissipation rate. There is no other study of the $8 \mathrm{~h}$ oscillation at this latitude. However, at Saskatoon (Manson and Meek, 1986) the amplitudes were also larger in the winter zonal component.

2. The semidiurnal tide is present below $88 \mathrm{~km}$ where it is suppressed somewhat during the wind reversal. There is strong evidence for this tidal mode in the energy dissipation rate well below the summer mesopause. The earlier Tromsø study (Manson and Meek, 1991) involved a 3-y climatology rather than a one year, due to lack of data, but the amplitude trends are generally similar, with lower values during the wind reversal.

3. The diurnal tide in the zonal wind is distinct below $85 \mathrm{~km}$ in the winter, is suppressed a little during the reversal and intensifies at all heights, even above the mesopause, in summer. This tide appears to be absent from the meridional component at $90 \mathrm{~km}$ and its upper boundary sinks in altitude from winter to summer. The reversal has less effect on this mode in the meridional component than the zonal. Probably coupled with the intensification of the zonal diurnal tide, the response in the energy dissipation rate also 

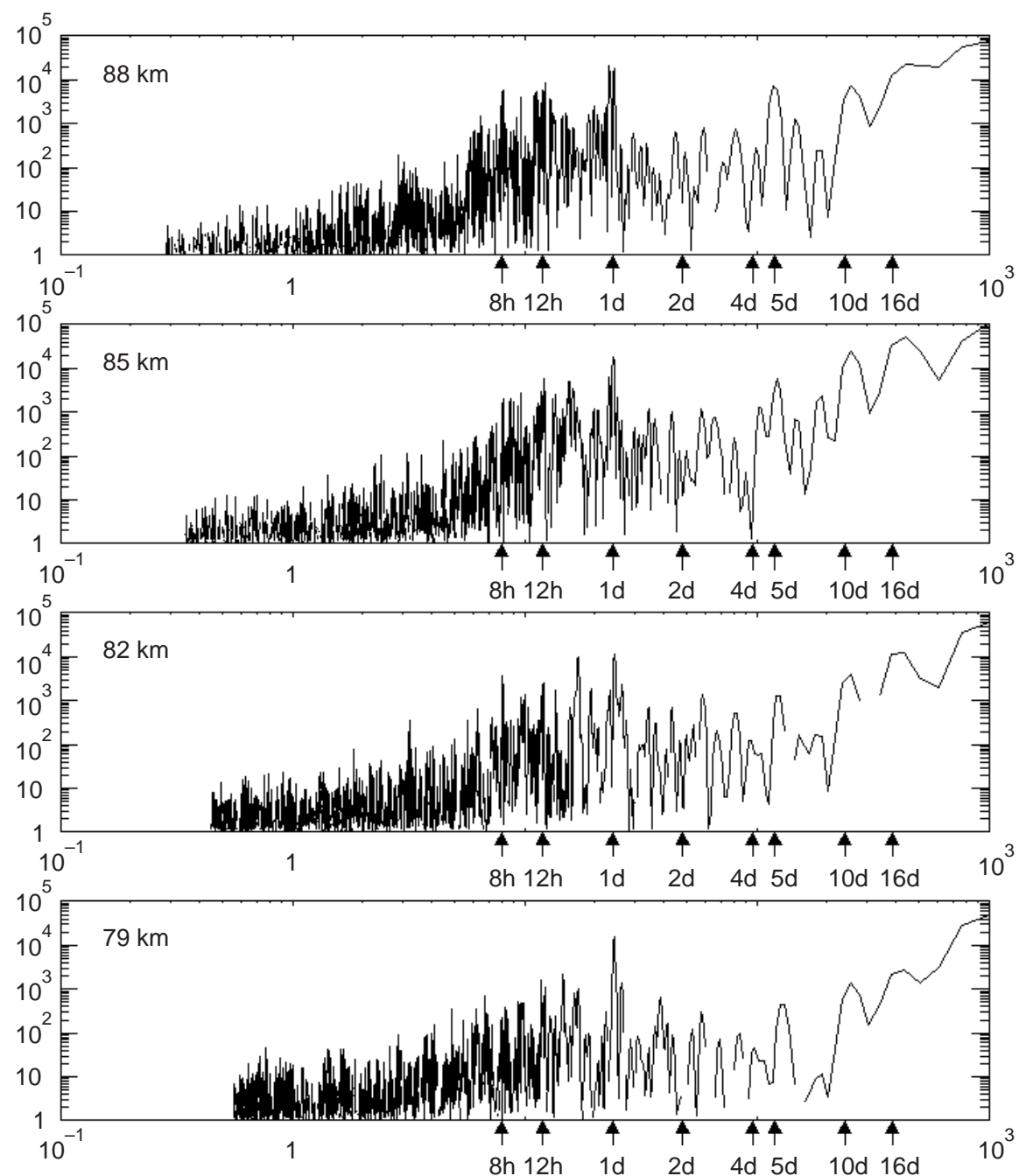

Fig. 5. As for Fig. 2 but for May 1997

increases through the spring but at the same time decreasing with altitude. The earlier Tromsø study (Manson and Meek, 1991) also shows maximum summer amplitudes near or below $90 \mathrm{~km}$

4. The quasi 2-day wave is weak in amplitude relative to the other modes but nevertheless is in evidence in the meridional wind and energy dissipation rate well below the summer mesopause. The Williams and Avery (1992) study for $65^{\circ} \mathrm{N}$ also shows larger summer amplitudes in the mesopause region.

The next four periods in Table 2 represent Rossby modes. That the periods are often prefixed with "quasi" reminds us that the observed periods of these waves are Doppler shifted by the background wind from the eigenvalues determined for an atmosphere simply rotating with the planet. Table 2 includes the eigen periods of the oscillations as can be deduced from Volland (1988). Here "eigen" implies that the vertical wave-number is infinite (again, Volland, 1988, p75), no Doppler shifting is present and no acceleration is provided by momentum deposition. We see from Fig. 1 that the $90 \mathrm{~km}$ mean wind in February and March is approximately $+10 \mathrm{~ms}^{-1}$, in April it is around zero, in May it is around $-10 \mathrm{~ms}^{-1}$ and in June it is around $-25 \mathrm{~ms}^{-1}$. We combine the average zonal wind speeds from the measurements at each height with the eigen periods from Table 2 to obtain the Doppler shifted eigen periods; it is for these periods that we now explicitly obtain amplitudes. It is of interest to compare these results with those obtained when using the quasi-periods in order to appreciate the effect of the varying background wind on the spectral signatures. Figure 9 uses the quasi periods from column 1 of Table 2, whereas Fig. 10 uses the Doppler-shifted eigenperiods (i.e. column 4). We see that the two figures are very similar suggesting that merely using the periods somewhat glibly referred to in the literature are adequate for such a study. It is important to note, at this stage, that we have taken the liberty of Doppler shifting modes according to the zonal winds given in Fig. 1; this approach is somewhat open to question because these winds cannot necessarily be assumed to be representative of all longitudes (the waves being planetary and not local.). Furthermore, as explained by Forbes (1995), producing Doppler shifted periods out of the eigenperiods is really only applicable to a height independent/latitude dependent prescribed wind distribution. Despite this, Volland (1988) has attempted to derive modified eigenperiods from the middle atmo- 

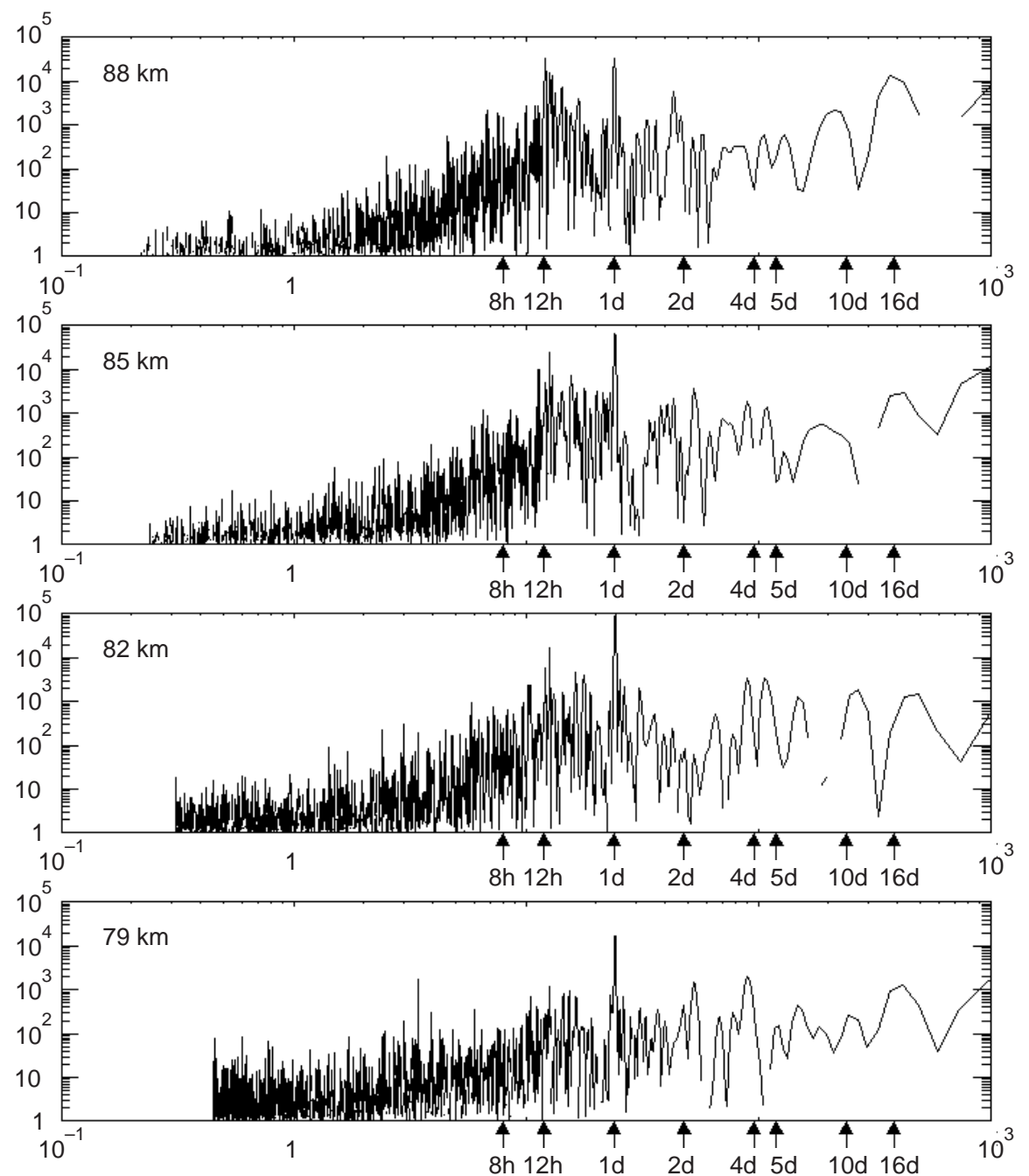

Fig. 6. As for Fig. 2 but for June 1997

Table 2.

\begin{tabular}{|c|c|c|c|}
\hline Mode & $\begin{array}{l}\text { Period (tides) } \\
\text { or quasi-period }\end{array}$ & Description & $\begin{array}{l}\text { Eigen-period } \\
\text { (days) }\end{array}$ \\
\hline 1 & $8 \mathrm{~h}$ tide & Terdiurnal tidal mode & 0.33 \\
\hline 2 & $12 \mathrm{~h}$ tide & Semidiurnal tide & 0.5 \\
\hline 3 & $24 \mathrm{~h}$ tide & Diurnal tide & 1.0 \\
\hline 4 & 2 day wave & $\begin{array}{l}\text { Mixed Rossby-gravity } \\
\text { asymmetric }\end{array}$ & 2.1 \\
\hline 5 & 4 day wave & $\begin{array}{l}\text { Rotational: Rossby } \\
1^{\text {st }} \text { symmetric }\end{array}$ & 3.7 \\
\hline 6 & 5 day wave & $\begin{array}{l}\text { Rotational: Rossby } \\
1^{\text {st }} \text { symmetric }\end{array}$ & 5.0 \\
\hline 7 & 10 day wave & $\begin{array}{l}\text { Rotational: Rossby } \\
1^{\text {st }} \text { asymmetric }\end{array}$ & 8.5 \\
\hline 8 & 16 day wave & $\begin{array}{l}\text { Rotational: Rossby } \\
2^{\text {nd }} \text { symmetric }\end{array}$ & 12.5 \\
\hline
\end{tabular}

sphere wind field similar to our approach. To illustrate the danger here, Forbes (1995) shows how a $20 \mathrm{~ms}^{-1}$ tropospheric wind is sufficient to convert the 12.5-day period into 16-day, quite aside from applying an observed mesospheric wind. Bearing these caveats in mind, let us review the salient features of Fig. 10 as we did for Fig. 7:
1. The 4-day wave appears as a winter upper mesosphere (but sub-mesopause) feature in both components of the wind. The mode dies away with the demise of the winter eastward wind during the course of March

2. The 5-day wave is apparent in a half a scale-height deep region around $87 \mathrm{~km}$ in winter. It descends and then disappears during March but re-emerges in May in the mid-mesosphere.

3. The 10-day wave is apparent in all three parameters in winter. It appears to be inhibited in the zonal wind and energy dissipation rate during the reversal period, only really manifesting itself again in May. In the meridional wind, however, the mode is strong in the upper mesosphere during February, weakening during March and then descending into the midmesosphere in April, after which it vanishes.

4. The 16-day wave seems restricted to little over a $10 \mathrm{~km}$ height regime centred on $82 \mathrm{~km}$. It is a strong feature of the zonal wind except in April when its absence is equally marked. The wave never really reestablishes itself in the meridional wind after the reversal. In contrast, however, it is only a feature of the energy dissipation rate after April, and then only well below the summer mesopause. 


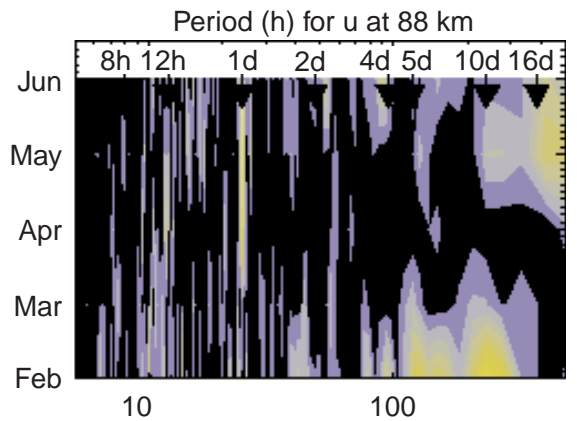

Period (h) for $\mathrm{u}$ at $85 \mathrm{~km}$

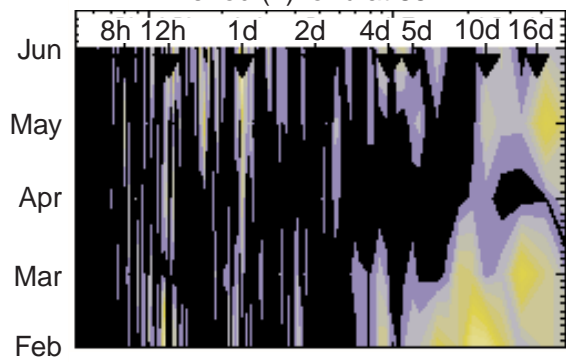

10

100

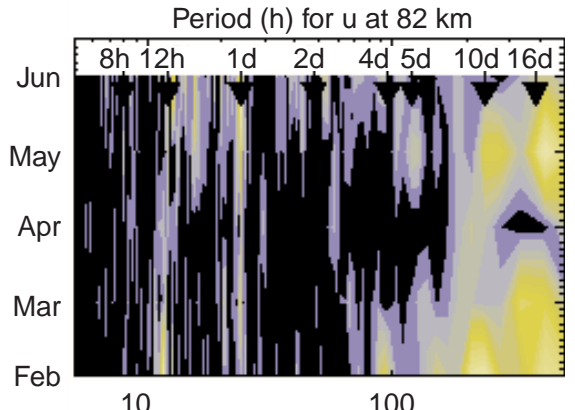

Period (h) for $\mathrm{u}$ at $79 \mathrm{~km}$

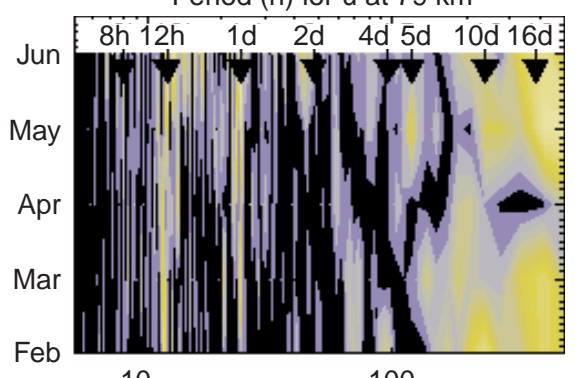

10

100

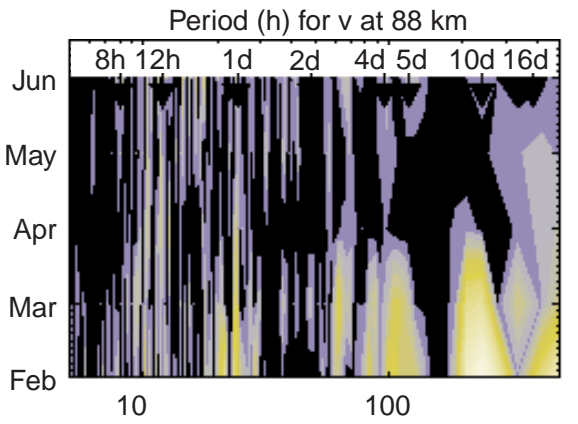

Period (h) for $\mathrm{v}$ at $85 \mathrm{~km}$

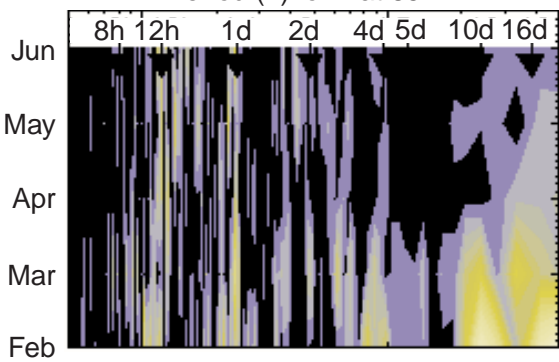

10

100

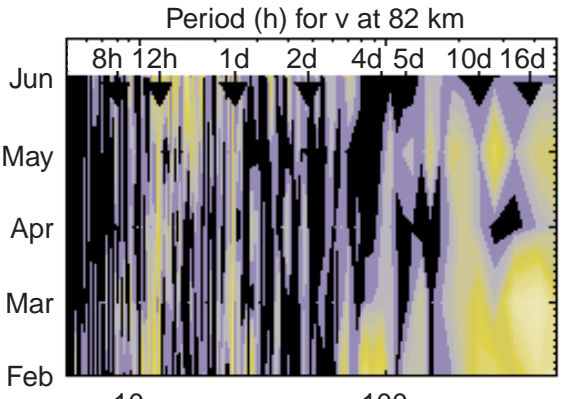

10

100

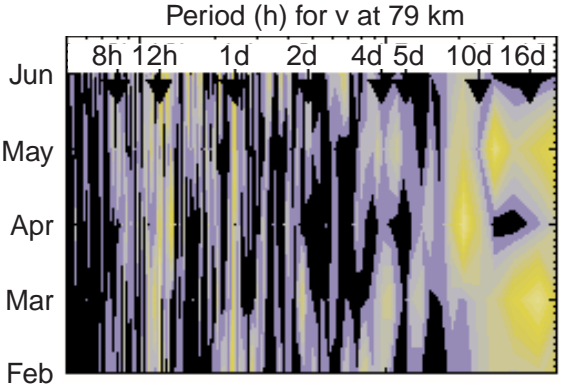

10

100

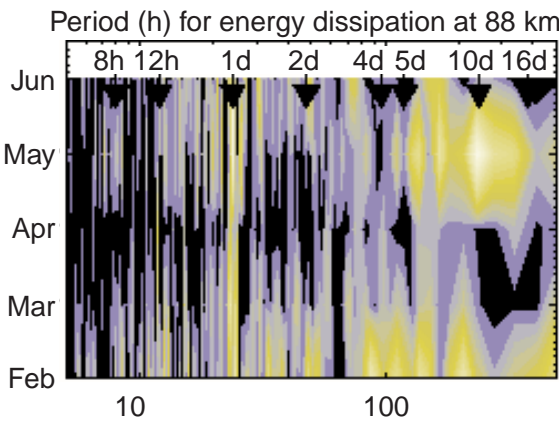

Period (h) for energy dissipation at $85 \mathrm{~km}$

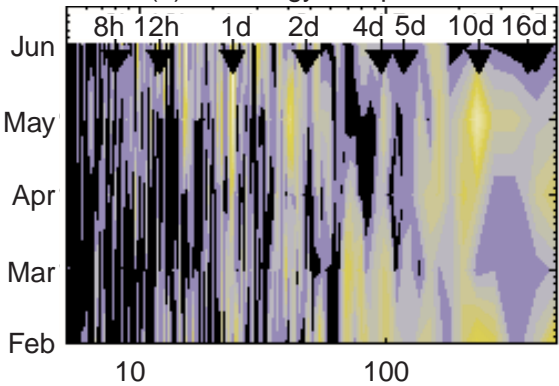

Period (h) for energy dissipation at $82 \mathrm{~km}$

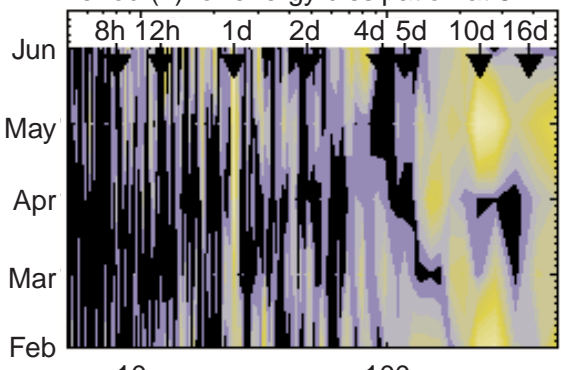

10

100

Period $(\mathrm{h})$ for energy dissipation at $79 \mathrm{~km}$

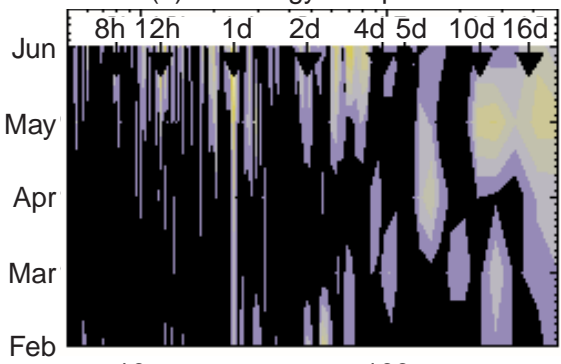

10

100
Fig. 7. Contours of spectral amplitude as functions of period and month. Data from the earlier figures are grouped according to altitude and this time the meridional component of the wind and the corresponding amplitude of an estimate of the turbulent energy dissipation rate (see text) are included

the EW-zonal dominates in the summer. The energy dissipation rate also maximises in summer. The observations are consistent with Williams and Avery (1992) (who show the zonal component only) and Espy et al. (1997) who both noted a summer maximum, but also with Forbes et al. (1995) who studied a winter 16-day wave event at several midlatitude locations. Again, Yi Luo (private communication) notes strong inter-annual variability in the 16day occurrence, with frequent winter maxima and occasional upper mesopause summer events at mid- 

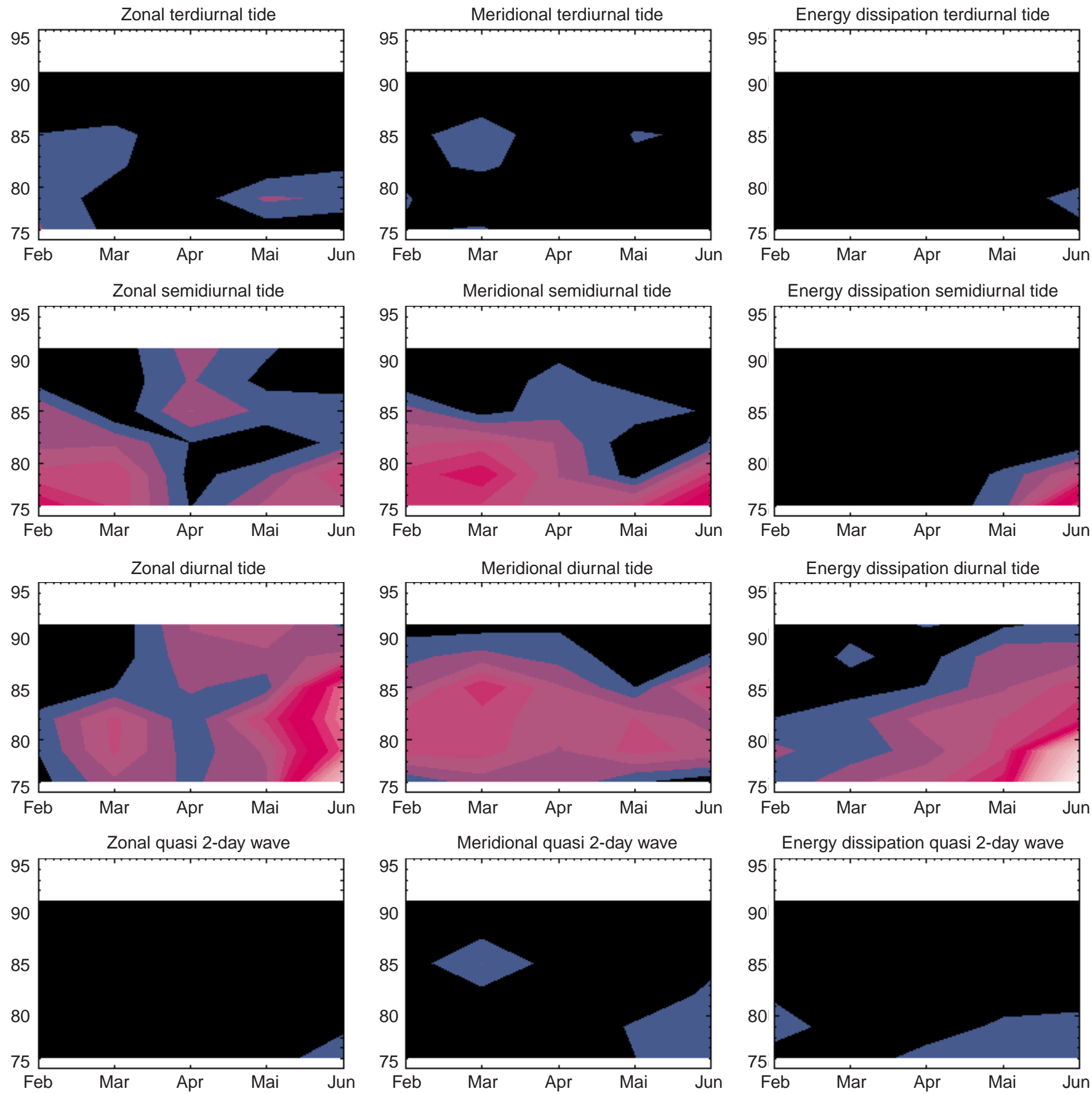

Energy dissipation quasi 2-day wave

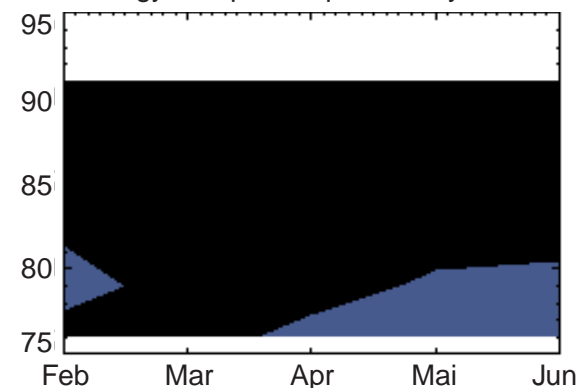

Fig. 8. Contours of spectral amplitude as functions of month and height for the tidal modes. Data for the two wind components and the

latitudes (Saskatoon, $52^{\circ} \mathrm{N}$ ). These waves have most probably propagated to the upper summer mesosphere from the winter hemisphere (Forbes et al., 1995).It will require global studies such as PSMOS (1998-2002) to better understand these oscillations/ waves more fully.

\section{Discussion}

Some overall features of the spectrum of the mesosphere dynamics as a function of height as spring progresses are energy dissipation rate are grouped according to the periods $8,12,24$ and $48 \mathrm{~h}$

worthy of note. Recall, first, however, that we are only examining the spring of 1997 , which a postiori may prove to be a pathological case. The diurnal tide, perhaps the least exotic of the modes examined here is somewhat surprisingly dominant, and is least affected by the background wind reversal. The semidiurnal tide, on the other hand, is restricted to lower altitudes than one might expect for high latitude (e.g. Forbes, 1995) and behaves curiously at these periods. It is important to note that the estimated energy dissipation rate is observed to be negligible below the summer mesopause, exhibiting an annual variation in the mesosphere itself. 

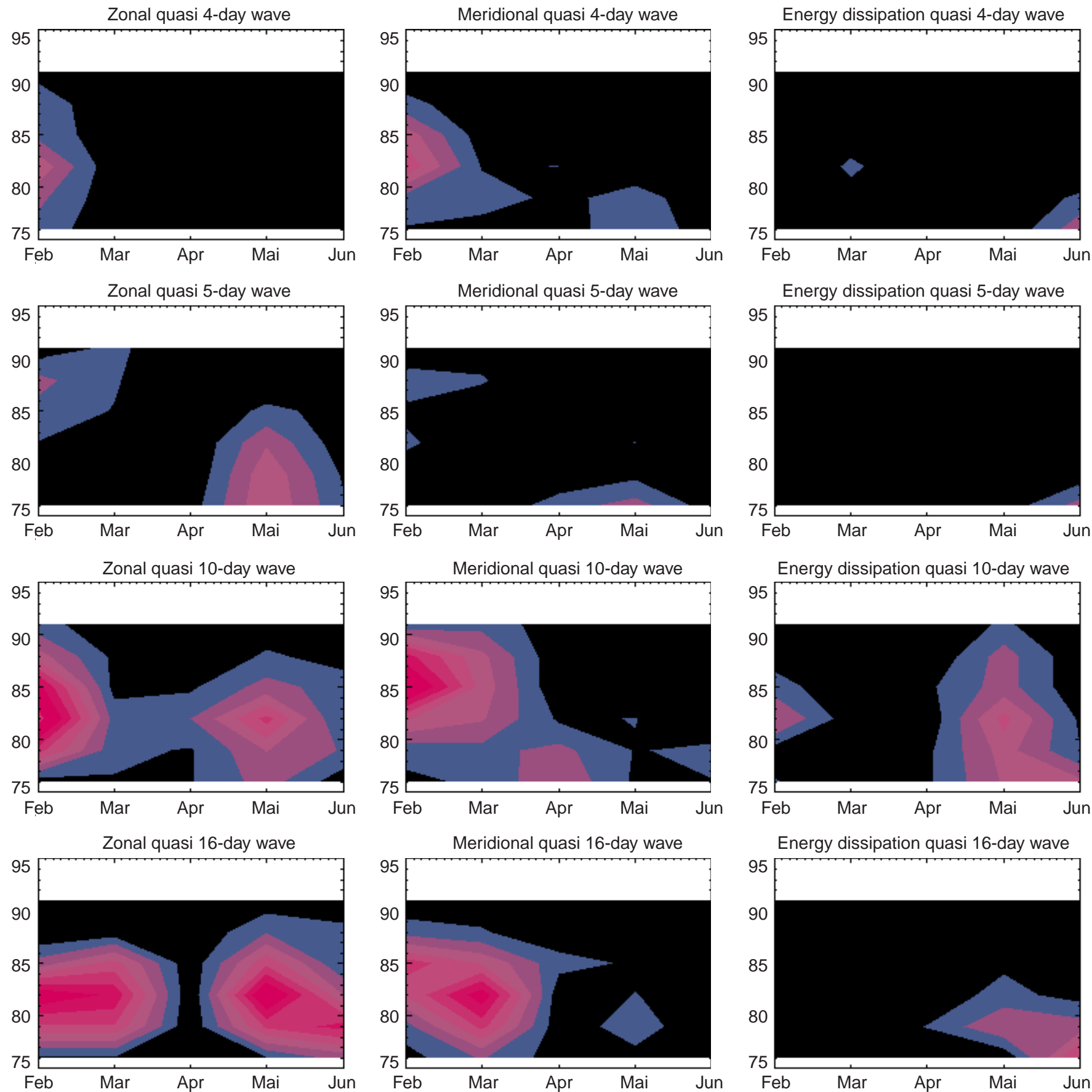

Fig. 9. As for Fig. 8, but for the Rossby modes with periods 4, 5, 10 and 16 days. Here the amplitudes are obtained at the quasi-periods

At $90 \mathrm{~km}$ it exhibits a semi-annual variability with an overall maximum in summer, a secondary maximum in winter and minima near the equinoxes (e.g. Hall et al., 1997). The overall magnitude of this parameter is expected to depend on the overall flux of gravity waves, which are represented by periods shorter than the shortest tidal modes addressed here. The background wind and its modulation by tidal and planetary wave dynamics will contribute to determining the atmospheric stability and therefore when and where shorter period gravity waves dissipate energy. The amplitudes in the spectra presented in this study should not be confused with the overall energy deposition, therefore. We can see that the energy dissipation is apparently coupled to both the diurnal and semidiurnal tides in the summer midmesosphere; the right hand side of Fig. 9 should not, therefore be interpreted as an indication of enhanced energy dissipation. Rather, overall low gravity wave activity at these heights in summer makes the coupling more obvious. The same warning applies to the 10 and 16 day waves: there is an interesting coupling between the large- and small-scale dynamics in summer.

Energy leakage from the mesosphere into the lower thermosphere appears to occur only for the diurnal tide, 

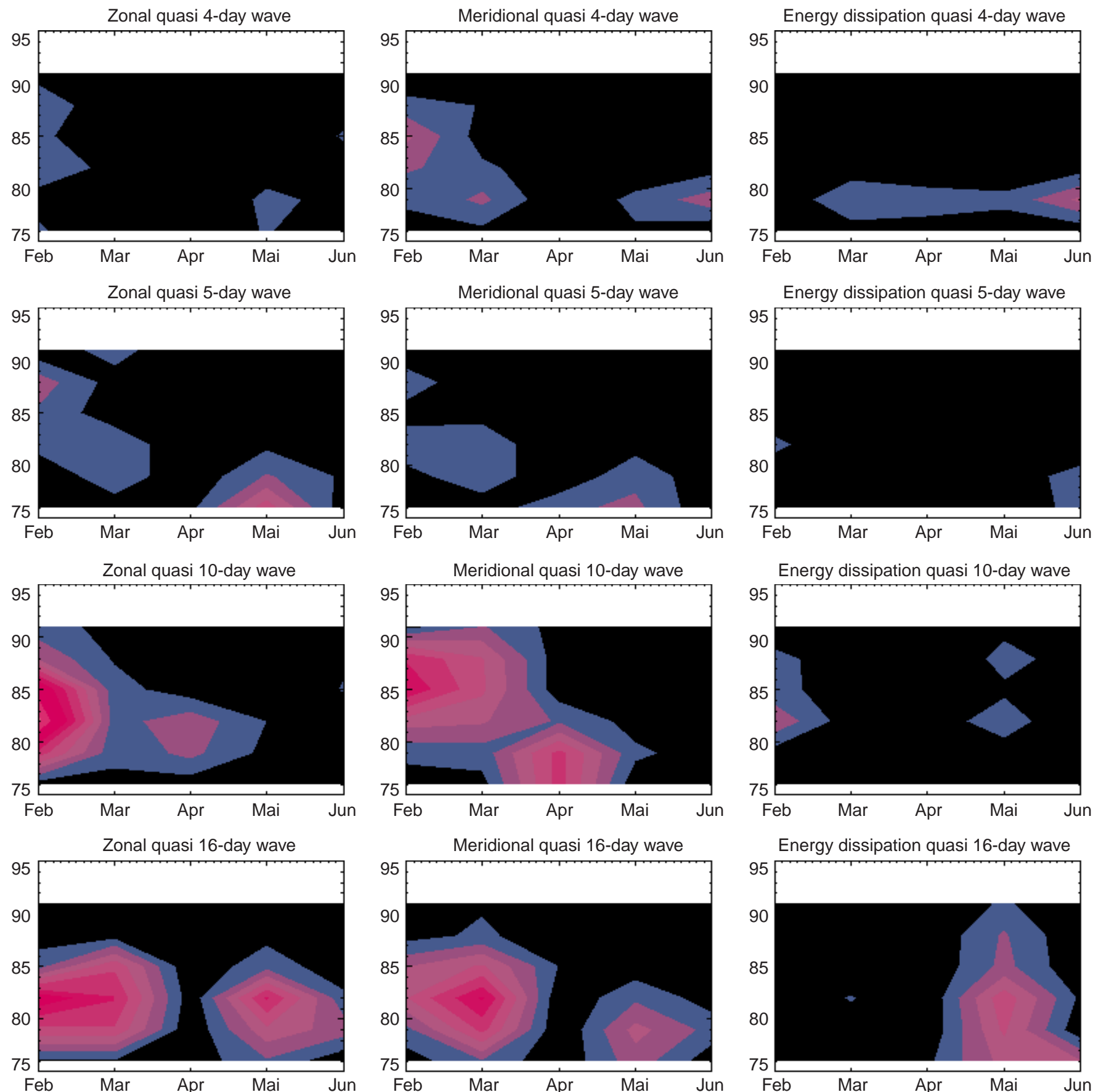

Energy dissipation quasi 16-day wave

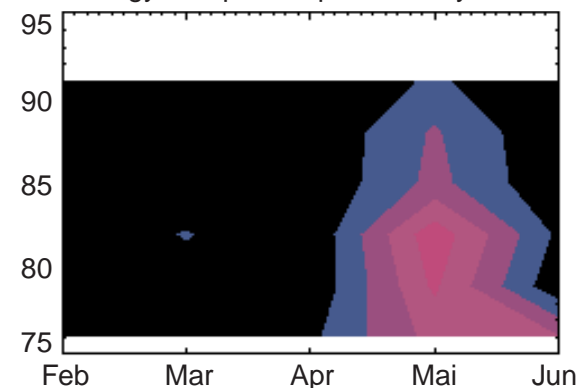

Fig. 10. As for Fig. 9, but using periods obtained by Doppler shifting the eigenperiods by the background wind

although there is some indication for the winter 10-day wave, and the equinox semidiurnal tide. All other modes appear to be bounded by the increasing stability of the mesopause.

The near-absence of the terdiurnal and 2-day modes in our data is striking.

Finally, the feature common to all heights and modes is that there is a general suppression of oscillation during April. Virtually every period is damped at most heights during this period and some modes even disappear. Subsequently, in May, the oscillations begin to re-assert themselves and, in some cases, modes peculiar to the summer state emerge. Around the zonal wind reversal, little Doppler shifting of waves will occur which could account for our failure to detect certain modes in April (the "valley"), however this would only apply to the planetary waves for which we have attempted to apply Doppler shifts.

Acknowledgements. The authors wish to thank the referees of this paper, C. Jacobi and R. Roper. The authors are similarly indebted to J. Forbes who has also provided valuable advice regarding Doppler shifting of eigenperiods.

Topical Editor F. Vial thanks C. Jacobi and R. Roper for their help in evaluating this paper. 


\section{References}

Avery, S. K., R. A. Vincent, A. Phillips, A. H. Manson and G. J. Fraser, High latitdude tidal behaviour in the mesosphere and lower thermosphere, J. Atmos. Terr. Phys., 51, 595-608, 1989.

Bremer, J., P. Hoffmann, A. H. Manson, C. E. Meek, R. Rüster and W. Singer, PMSE observations at different frequencies in Northern Europe during summer 1994, Ann. Geophysicae, 14, 1317-1327, 1997.

Briggs, B. H., The analysis of spaced sensor records by correlation techniques, Handbook MAP, 13, 166-186, 1984.

Espy, P. J., J. Stegman and G. Witt, J., Interannual variations of the quasi-16-day oscillation in the polar summer mesospheric temperature, J. Geophys Res., 102, 1983-1990, 1997.

Forbes, J. M., Tidal and planetary waves, in the upper mesosphere and lower thermosphere: a review of experiment and theory, Geophysical Monograph 87, 356 pp, 1995.

Forbes, J. M., M. E. Hagan, S. Miyahara, F. Vial, A. H. Manson and Y. I. Portnyagin, Quasi 16-day oscillation in the mesosphere and lower thermosphere, J. Geophys. Res., 100, 9149-9163, 1995.

Hall, C. M., T. A. Blix, E. V. Thrane and F.-J. Lübken, Seasonal variation of mesospheric turbulent kinetic energy dissipation rates at $69^{\circ}$ N, Proc. 13th ESA Symp., 505-509, 1997.

Hall, C. M., C. E. Meek and A. H. Manson, Turbulent energy dissipation rates from the University of Tromsø / University of Saskatchewan MF radar, J. Atmos. Solar-Terr. Phys., 60, 437440, 1998.
Hocking, W. K., Strengths and limitations of MST radar measurements of middle-atmosphere winds, Ann. Geophysicae, 15, 1111-1122, 1997.

Lomb, N. R., Least-squares frequency analysis of unequally spaced data, Astrophys. Space Sci., 39, 447-462, 1976.

Lübken F.-J., and U. von Zahn, Thermal structure of the mesopause region at polar latitudes, J. Geophys. Res., 96, 20 841-20 857, 1991.

Manson, A. H., and C. E. Meek, Dynamics of the middle atmosphere at Saskatoon $\left(52^{\circ} \mathrm{N}, 107^{\circ} \mathrm{W}\right)$ : a spectral study during 1981,1982, J. Atmos. Terr. Phys., 48, 1039-1053, 1986.

Manson, A. H., C. E. Meek, H. Teitelbaum, F. Vial, R. Schminder, D. Kürschner, M. J. Smith, G. J. Fraser, and R. R. Clark, Climatologies of semi-diurnal and diurnal tides in the middle atmosphere $(70-110 \mathrm{~km})$ at middle latitudes $\left(40-55^{\circ}\right), \mathrm{J}$. Atmos. Terr. Phys., 51, 579-594, 1989.

Manson, A. H., and C. E. Meek, Climatologies of mean winds and tides observed by medium frequency radars at Tromsø $\left(70^{\circ} \mathrm{N}\right)$ and Saskatoon $\left(52^{\circ} \mathrm{N}\right)$ during 1987-1989, Can. J. Phys., 69, 966-975, 1991.

Manson, A. H. and C. E. Meek, Gravity wave spectra and direction statistics for the mesosphere as observed by MF radars in the Canadian Prairies $\left(49^{\circ} \mathrm{N}-52^{\circ} \mathrm{N}\right)$ and at Tromsø $(690 \mathrm{~N}), J$. Atmos. Solar-Terr. Phys., 59, 993-1009, 1997.

Volland, H., Atmospheric Tidal and Planetary Waves, Kluwer, Dordrecht, The Netherlands, 348 pp., 1988.

Williams, C. R. and S. K. Avery, Analysis of long-period waves using the mesosphere-stratosphere-troposphere radar at Poker Flat, Alaska, J. Geophys. Res., 97, 20 855-20 861, 1992. 